\title{
PREVALENCE AND CORRELATES OF ERECTILE DYSFUNCTION: RESULTS OF THE BRAZILIAN STUDY OF SEXUAL BEHAVIOR
}

\author{
EDSON DUARTE MOREIRA, JR, CARMITA HELENA NAJJAR ABDO, ELIANA BARRETO TORRES, \\ CARLOS FERNANDO LISBOA LÔBO, AND JOÃO ANTÔNIO SARAIVA FITTIPALDI
}

\begin{abstract}
Objectives. To determine the prevalence of erectile dysfunction (ED) and explore its potential sociodemographic, medical, and lifestyle correlates.

Methods. While attending the "Health Awareness Fair" in nine major cities in Brazil, 1286 men completed a questionnaire regarding ED, demographic data, and medical conditions. ED was assessed by a single global self-rating question, in which subjects were asked to describe themselves as able to achieve and maintain an erection good enough for sexual intercourse always, usually, sometimes, or never, and the responses were used to classify the subjects as having no, minimal, moderate, or complete ED, respectively. Age-adjusted bivariate and multivariate analyses were carried out to calculate the prevalence odds ratios and 95\% confidence intervals for the potential covariates.

Results. Overall, $46.2 \%$ of men reported some degree of ED (minimal $31.5 \%$, moderate $12.1 \%$, complete 2.6\%). The prevalence of complete ED increased 10 times from $1 \%$ to $11 \%$ between subjects younger than 40 and older than 70 years; moderate ED rose from $8 \%$ to $27 \%$, and minimal ED remained constant at approximately $31 \%$. In bivariate age-adjusted analyses, low educational attainment, black race/ethnicity, homo/bisexuality, and a history of diabetes, hypertension, or depression were significantly $(P<0.05)$ associated with an increased prevalence of ED. In the multivariate logistic regression model, these variables remained significantly associated with ED.
\end{abstract}

Conclusions. The results of our study show that ED is a major health problem in Brazil and both the severity and prevalence increase with age. The medical, sociodemographic, and lifestyle variables associated with ED may alert physicians to patients who are at risk of ED, as well as offer clues to the etiology of ED. UROLOGY 58: 583-588, 2001. () 2001, Elsevier Science Inc.

$I^{n}$ n 1992, a meeting of the Consensus Development Panel on Impotence at the National Institutes of Health defined erectile dysfunction (ED) as the persistent inability to attain and maintain a penile erection adequate for satisfactory sexual performance. ${ }^{1}$ The term "impotence" with its pejorative and nonspecific meaning was replaced by the

This study was supported by a research grant from Laboratórios Pfizer, São Paulo, Brazil

From the Núcleo de Epidemiologia e Estatística, Centro de Pesquisas Gonçalo Moniz, Fundação Oswaldo Cruz, Salvador; Departamento de Psiquiatria, Faculdade de Medicina da Universidade de São Paulo, São Paulo; Instituto Brasileiro de Geografia e Estatística, Salvador; and Laboratórios Pfizer, São Paulo, Brazil

Reprint requests: Edson Duarte Moreira, Jr., M.D., Praça Dois de Julho 156, Apt. 2102, Salvador, Bahia, Brazil, 40.080-120

Submitted: March 23, 2001, accepted (with revisions): May 23, 2001 more precise term "erectile dysfunction." It is estimated that more than 25 million men aged 40 to 70 years will be affected by this condition in the United States by $2005 .{ }^{2}$ In Brazil, the results of the first population-based study on ED, done in 1998, suggested that approximately $40 \%$ of the Brazilian male population in this same age range have some degree of ED. ${ }^{3}$ Even though this sexual dysfunction is not life threatening, it should not be considered a benign disorder, as it may have a strong negative effect on patients' interpersonal relationships and compromise their well-being and quality of life. ${ }^{4}$

Recently, new drug classes have been identified that offer significant therapeutic potential for ED. 5,6 These pharmacologic advances have sparked professional and public interest in ED, generating an increasing demand for clinical ser- 
vices related to ED. Despite these facts, the epidemiologic data on ED are relatively scarce. The need for population-based data referring to the prevalence, determinants, and consequences of ED is urgent. ${ }^{1}$ Information of this nature would be very helpful in the development of appropriate strategies for the deployment of resources and rendering of services related to ED.

In the present study, we analyzed data collected from several metropolitan centers in Brazil to estimate the prevalence of ED. The role of sociodemographic characteristics, medical conditions, lifestyle, and cultural aspects as ED determinants was also investigated.

\section{MATERIAL AND METHODS}

\section{SAMPLE SELECTION}

The study sample comprised men passing by popular public places such as beaches, squares, and parks. They were invited to participate in this survey while attending the program "Health Awareness Fair," an event that occurred between February and April 2000 in these locations. This project was designed to offer education and general information on health and disease prevention. All men older than 18 visiting the Fair were invited by one of the previously trained monitors to participate in an anonymous survey on health status, lifestyle, and sexuality. A consecutive sample of approximately 125 men was selected from each site, except in Rio de Janeiro and Curitiba, where 86 and 75 individuals were recruited, respectively.

\section{STUDY Sites}

The "Health Awareness Fair" was conducted in nine major Brazilian cities (São Paulo, Rio de Janeiro, Salvador, Porto Alegre, Curitiba, Santos, Recife, Belo Horizonte, and Ribeirão Preto), in seven different states. The event lasted one weekend in each city, except in São Paulo, where three sessions took place.

\section{Data Collection}

The information was gathered by a standardized self-completed questionnaire that the men completed in 15 to 20 minutes in a private cabin. The data collection instrument has been published elsewhere, ${ }^{7}$ and includes questions on demographic data (eg, age, profession, religion), general health (self-report of medical conditions), lifestyle, and sexual behavior. In regard to the ED assessment, the subjects were requested to choose one category (always, usually, sometimes or never being able to achieve and maintain an erection satisfactory for sexual performance) that best described them. The answers were then used to classify the respondents into one of the following categories: no, minimal, moderate, or complete ED. Thus, the presence of ED was assessed by the individual in terms of a single global question derived directly from the ED definition proposed at the National Institutes of Health Consensus Conference. ${ }^{1}$ The statistical validation of this subjective approach was established in the Massachusetts Male Aging Study (MMAS) calibration study. ${ }^{8}$ In addition, Derby et al. ${ }^{9}$ validated the use of a single self-assessment question against two well-established ED measures, the International Index of Erectile Function ${ }^{10}$ and the Brief Male Sexual Function Inventory. ${ }^{11}$

\section{Statistical Analysis}

The completed questionnaires were double-entered into a computerized database to check for errors and internal consistency. In all bivariate and multivariate analyses, ED was dichotomized as "none" or "minimal" and "moderate" or "complete." For each independent variable, crude and ageadjusted bivariate odds ratios and 95\% confidence intervals were calculated. The statistical significance (two-tailed $P$ $\leq 0.05$ ) was assessed by the chi-square test for categorical variables and by Student's $t$ test and analysis of variance for continuous variables. In the multivariate logistic regression analysis, full models were fitted, and the nonsignificant $(P>0.1)$ variables were eliminated in a stepwise, backward elimination algorithm, least significant first, to determine the final model. Exceptions were made for the medical variables, which were forced into the model because they were of primary interest in the study.

\section{RESULTS}

Of the 1286 participants in the survey, 116 (9\%) failed to answer the question on ED and were excluded. The remaining 1170 were used for this analysis. The excluded subjects were similar to the remaining ones in regard to age, education, and prevalence of medical conditions. Table I shows selected characteristics of the study population. The mean age (standard deviation) of men in our sample was 39.3 (12.9) years. Their age distribution was similar to that of the Brazilian male population. ${ }^{12}$ The participants in our study had a higher education than average Brazilian men, and the frequency distribution of race and religion in our sample was comparable to that found in Brazil overall. ${ }^{12}$

\section{PrevalenCe}

Overall, 540 men (46.2\%) reported some degree of ED; the frequency of minimal, moderate, and complete dysfunction was $31.5 \%, 12.1 \%$, and $2.6 \%$, respectively. After standardizing these rates for the distribution of age and education in the Brazilian population, we estimated the prevalence of ED in Brazil to be $48.8 \%$, with $26.6 \%$ minimal, $18.3 \%$ moderate, and $3.9 \%$ complete (Table II).

\section{Age Dependence}

The relationship of age and ED is illustrated in Figure 1 . The frequency of moderate and complete ED increased with age, from $8.3 \%$ and $1.1 \%$, respectively, in subjects younger than 40 years old, to $27.8 \%$ and $11.1 \%$ among men 70 years old and older. The prevalence of minimal dysfunction remained stable at approximately $32 \%$. The association between age and ED was always statistically significant $(P<0.001)$ when tested by multivariate analysis along with other possible predictors of ED. No other variable, whether it correlated with age or not, was able to diminish the predictive power of age. 
TABLE I. Selected sociodemographic, physical, and medical characteristics of a population-based sample of 1170 men, in Brazil 2000

\begin{tabular}{|c|c|c|}
\hline & $\begin{array}{l}\% \text { of the } \\
\text { Sample }\end{array}$ & $\begin{array}{c}\text { \% of the } \\
\text { Brazilian Male } \\
\text { Population* }\end{array}$ \\
\hline \multicolumn{3}{|l|}{ Age (yr) } \\
\hline $18-39$ & 55.7 & 58.6 \\
\hline $40-49$ & 22.4 & 18.1 \\
\hline $50-59$ & 14.0 & 11.2 \\
\hline $60-69$ & 6.4 & 7.3 \\
\hline $70+$ & 1.5 & 4.8 \\
\hline \multicolumn{3}{|l|}{ Education $(\mathrm{n}=1157)$} \\
\hline Primary school or less & 15.9 & 74.2 \\
\hline High school (graduate or some) & 41.4 & 17.2 \\
\hline College (graduate or some) & 42.7 & 8.6 \\
\hline \multicolumn{3}{|l|}{ Race $(n=1156)$} \\
\hline White & 58.1 & 56.5 \\
\hline Mixed & 35.3 & 37.7 \\
\hline Black & 6.1 & 5.2 \\
\hline Other & 0.5 & 0.7 \\
\hline \multicolumn{3}{|l|}{ Marital status ( $\mathrm{n}=1159)$} \\
\hline Married or living with partner & 59.1 & 63.4 \\
\hline Single & 32.0 & 29.8 \\
\hline Divorced, separated & 8.1 & 5.7 \\
\hline Widowed & 0.8 & 1.1 \\
\hline \multicolumn{3}{|l|}{ Religious affiliation $(\mathrm{n}=1147$ ) } \\
\hline Catholic & 67.6 & 76.4 \\
\hline Protestant & 12.2 & 9.1 \\
\hline Espiritist & 10.6 & 7.6 \\
\hline Other & 5.4 & 3.1 \\
\hline None & 4.2 & 3.8 \\
\hline \multicolumn{3}{|l|}{ Sexual orientation $(n=1130)$} \\
\hline Heterosexual & 91.6 & \\
\hline Bisexual & 4.8 & \\
\hline Homosexual & 3.6 & \\
\hline \multicolumn{3}{|l|}{ Medical conditions } \\
\hline Depression & 16.3 & \\
\hline Hypertension & 15.8 & \\
\hline Dyslipidemia & 12.6 & \\
\hline Ulcer & 7.9 & \\
\hline Diabetes mellitus & 6.1 & \\
\hline Heart disease & 3.1 & \\
\hline * According to the 1996 National Census Data. & & \\
\hline
\end{tabular}

\section{Age-Adjusted Bivariate Associations}

The age-adjusted bivariate associations between ED and the potential covariates are presented in Table III. Education attainment was inversely associated with ED; black race compared with white was also associated with ED, but mixed race was not. Homosexual/bisexual men presented with a significantly higher ED prevalence than did heterosexuals. Religious affiliation and marital status were not associated with ED. Men reporting a medical diagnosis of diabetes, hypertension, or depression were more likely to report ED, but those with a history of dyslipidemia, heart disease, or peptic ulcer were not.

\section{Multivariate AnAlysis}

The results found in the multivariate analysis final model are also depicted in Table III. Age correlated strongly with ED (odds ratio $=1.05,95 \%$ confidence interval 1.03 to 1.06) for each year of increment in age. Reporting of black race and homo/bisexual orientation remained associated with $\mathrm{ED}$, and education also continued to be inversely associated with ED. Similar to the results of the age-adjusted bivariate analysis, a self-report of diabetes, hypertension, and depression were significantly associated with ED, and heart disease, dyslipidemia, and peptic ulcer were not. 


\section{TABLE II. Prevalence of erectile dysfunction in the study population, Brazil 2000 $(n=1170)$}

\begin{tabular}{lcc}
\hline $\begin{array}{l}\text { Erectile } \\
\text { Dysfunction }\end{array}$ & $\begin{array}{c}\text { Sample } \\
\text { Prevalence (\%) }\end{array}$ & $\begin{array}{c}\text { Brazilian Population } \\
\text { Prevalence (\%)* }\end{array}$ \\
\hline Absent & 53.8 & 51.2 \\
Present & 46.2 & 48.8 \\
$\quad$ Minimal & 31.5 & 26.6 \\
Moderate & 12.1 & 18.3 \\
Complete & 2.6 & 3.9 \\
* Standardized rates for the age and education distribution of the Brazilian male \\
population.
\end{tabular}

\section{COMMENT}

Our data indicate a high prevalence of ED (46.2\%) in a large sample of men from different regions in Brazil. Applying these rates to the Brazilian population, we estimate that currently more than 25 million men 18 years old or older have some degree of ED and 11.3 million have moderate to complete ED. These estimates suggest that ED is a common condition and a public health concern in Brazil.

The prevalence of ED we found is similar to the $40 \%$ reported in a study of 602 men in the only population-based survey conducted in Brazil before ours. ${ }^{3}$ These rates are also comparable to those reported in two studies done in the United States: $52 \%$ in the MMAS, ${ }^{13}$ a survey in a random sample of 1290 men 40 to 70 years old living in the cities and villages near Boston, Massachusetts, and $46.3 \%$ in a population-based survey of approximately 1650 men 50 to 76 years old in a rural zone of New York State. ${ }^{14}$ Similar ED rates were also found in France, where $39 \%$ of men aged 18 to 70 years reported $\mathrm{ED},{ }^{15}$ and in Thailand, where a study using a sample of 1250 men aged 40 to 70 revealed an ED prevalence of $37.5 \% .{ }^{16}$
In our survey, as in previous studies, ${ }^{13,16,17}$ ED was an age-dependent condition. The age increase was largely related to both the prevalence and severity of ED. This association remained true after all other variables that correlated significantly with ED were controlled for.

Education was inversely related to ED in our survey. In the MMAS longitudinal study, ${ }^{18}$ the ageadjusted risk of developing ED was greater among less educated men (odds ratio $=1.46,95 \%$ confidence interval 1.02 to 2.08). Education is commonly used as a proxy of socioeconomic status (SES) in population surveys. Despite the recognition of the association between a low SES and a broad range of health issues, the relationship between SES and ED has not been well established. In a recent study, Aytaç et al. ${ }^{19}$ suggested that the effect of SES on ED was, in part, mediated by its influence on lifestyle factors and medical conditions. Education in our survey was a surrogate for a number of social disparities that we could not directly measure with our data. More studies including broader SES measures at the individual, home, and neighborhood level are warranted to understand the mechanisms by which SES affects health conditions such as ED.

In our survey, men reporting black race presented with a higher prevalence of ED. A study in four American cities, including 1680 men age 40 years or older, showed that ED was not dependent on ethnic group. ${ }^{20}$ Although our results persisted in the multivariable analysis, we cannot rule out a residual confounding effect of SES with this result, because the limited assessment of SES may have led to a less than perfect control of this confounding variable. In our study sample, homo/bisexual orientation was associated with ED. It is possible that this finding reflects

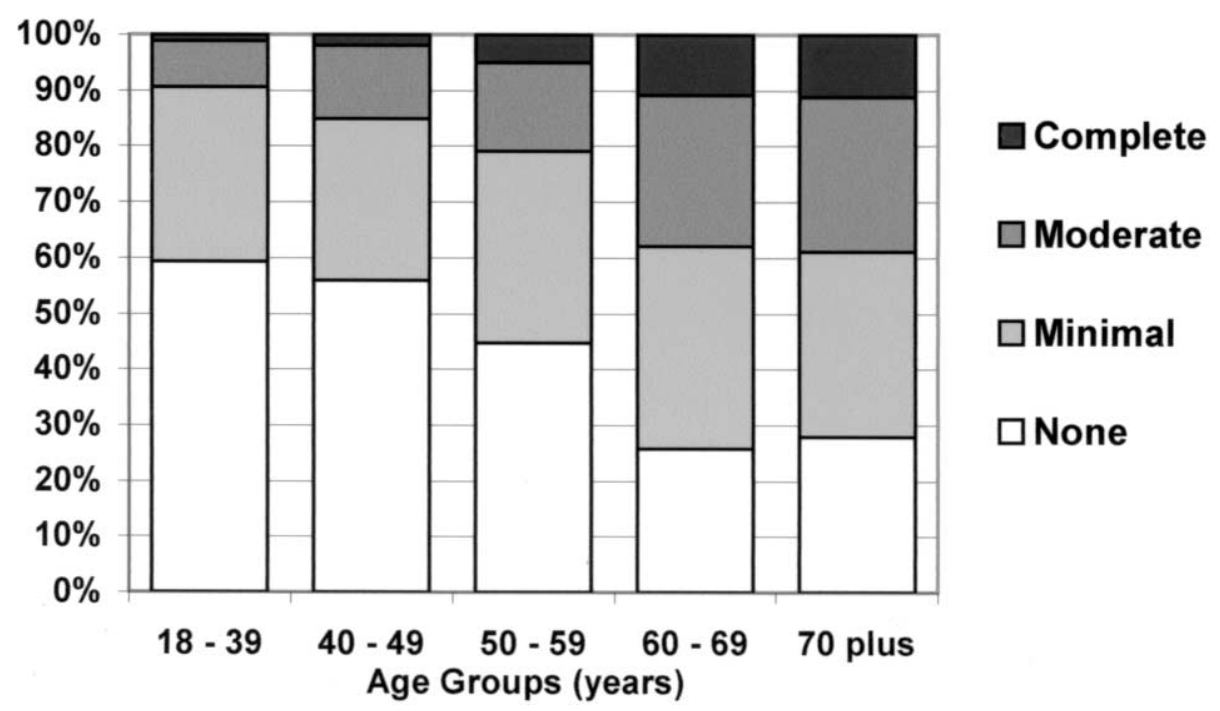

FIGURE 1. ED prevalence and severity by age, Brazil $2000(n=1170)$. 
TABLE III. Prevalence odds ratios for moderate or complete ED vs. no or minimal ED of selected characteristics in 1170 men, Brazil 2000

\begin{tabular}{|c|c|c|}
\hline Characteristic & $\begin{array}{c}\text { Age-Adjusted } \\
\text { Bivariate } \\
\text { OR }(95 \% \mathrm{CI})\end{array}$ & $\begin{array}{c}\text { Multivariate } \\
\text { OR } \\
(95 \% \mathrm{CI})^{*}\end{array}$ \\
\hline Age (1-yr increment) & - & $1.05(1.03-1.06)^{\dagger}$ \\
\hline \multicolumn{3}{|l|}{ Education } \\
\hline Post-secondary school & 1 (reference) & 1 (reference) \\
\hline High school (some or graduate) & $2.08(1.38-3.16)^{\dagger}$ & $2.11(1.37-3.25)^{\dagger}$ \\
\hline Primary school (some or graduate) & $3.65(2.28-5.83)^{\dagger}$ & $3.38(2.06-5.54)^{\dagger}$ \\
\hline \multicolumn{3}{|l|}{ Race } \\
\hline White & 1 (reference) & 1 (reference) \\
\hline Mixed & $1.27(0.78-2.05)$ & $0.89(0.51-1.51)$ \\
\hline Black & $2.15(1.29-3.61)^{\ddagger}$ & $1.72(1.00-2.98)^{\S}$ \\
\hline \multicolumn{3}{|l|}{ Marital status } \\
\hline Never married & 1 (reference) & - \\
\hline Married or living with partner & $0.82(0.53-1.28)$ & - \\
\hline Divorced, widowed, separated & $0.50(0.24-1.06)$ & - \\
\hline Religious affiliation (any) & $0.74(0.37-1.52)$ & - \\
\hline Sexual orientation (homo/bisexual) & $2.06(1.19-3.56)^{\S}$ & $1.99(1.12-3.56)^{\S}$ \\
\hline \multicolumn{3}{|l|}{ Medical conditions } \\
\hline Diabetes & $2.18(1.25-3.82)^{\ddagger}$ & $2.05(1.12-3.77)^{\S}$ \\
\hline Hypertension & $2.30(1.54-3.43)^{\dagger}$ & $1.96(1.26-3.05)^{\ddagger}$ \\
\hline Heart disease & $0.84(0.35-2.04)$ & $0.61(0.23-1.65)$ \\
\hline Dyslipidemia & $1.22(0.77-1.93)$ & $0.92(0.54-1.56)$ \\
\hline Ulcer & $0.94(0.52-1.71)$ & $0.95(0.50-1.81)$ \\
\hline Depression & $1.87(1.25-2.81)^{\ddagger}$ & $1.71(1.09-2.67)^{\S}$ \\
\hline \multicolumn{3}{|c|}{$\begin{array}{l}\text { KEY: } E D=\text { erectile dysfunction; } O R=\text { odds ratio; } C I=\text { confidence interval. } \\
{ }^{*} \text { For the variables included in the final multivariate logistic regression model. } \\
{ }^{+} \mathrm{P}<0.001 . \\
{ }^{\mathrm{P}} \mathrm{P}<0.01 . \\
{ }^{\mathrm{P}} \mathrm{P}<0.05\end{array}$} \\
\hline
\end{tabular}

differences in the perception of and attitude toward ED among homo/bisexual men.

Several studies have repeatedly shown ED to be more prevalent in diabetic individuals, with estimates ranging from $35 \%$ to $75 \% .{ }^{21-23}$ We found moderate/complete ED in $37 \%$ of the participants with diabetes. Which of the several aspects of diabetes is the direct causative agent of ED is controversial. Vascular disease is frequently mentioned. ${ }^{24}$ In addition, autonomic neuropathy, gonadal dysfunction, and vascular endothelium or neurogenic impairment of penile smooth muscle relaxation have also been implicated. ${ }^{23,25}$

Cardiovascular disease has been associated with ED in several studies. ${ }^{26,27}$ Our results showed an association between ED and a history of hypertension, but it failed to demonstrate a significant relationship with a history of heart disease or dyslipidemia. Because we had to rely on self-report, it is possible that subjects unaware of their existence have underreported medical conditions that are frequently asymptomatic or underdiagnosed. This would likely result in nondifferential misclassification and bias the results toward the null.

Depression was associated with ED in our study population, irrespective of age and the presence of other ED risk factors. Using the MMAS data, Araujo et al. ${ }^{28}$ found a strong association between ED and the presence of depressive symptoms. Even though the correlation between ED and depression is well documented, the causal relationship between both is sometimes imprecise and most probably bidirectional (ie, ED may follow depression and depression may be a consequence of ED). ${ }^{29,30}$

\section{Study Merits and Limitations}

The main strength of this study was its large, population-based sample drawn from nine major cities of seven states, widely representative of the Brazilian male population. This allowed us to determine the prevalence and degree of ED accurately, thus providing reliable estimates on the number of men with this sexual dysfunction in Brazil for the first time. The assessment of the presence of ED by the subject himself in terms of a single global question allowed our results to be compared with most of the epidemiologic studies performed on ED. In addition, the anonymous and private approach to the data collection allowed us to explore the potential correlates of ED with minimal informational and observation bias. 
The main limitation was that, because of its cross-sectional design, the data collection was carried out solely by a self-completed questionnaire. Thus, the assessment of medical conditions was limited to self-report. Commonly asymptomatic or oligosymptomatic diseases may be substantially underreported, which is likely to result in nondifferential classification error and attenuation of the associations measured.

\section{CONCLUSIONS}

In Brazil, as in other countries, ED is a common condition, whose prevalence and severity increases with age. The correlates of ED identified in our population are consistent with some, but not all, of the previous studies on the epidemiology of this sexual dysfunction. Future research should include the objective assessment of the presence of medical conditions potentially associated with ED, particularly those that are frequently asymptomatic or underdiagnosed (eg, diabetes, hypertension, heart disease). In addition, studies on the incidence of ED according to population are warranted to test prospectively the hypothesis generated by the associations encountered in this cross-sectional study. We hope that the characteristics correlated with ED identified here may help health professionals in the individual assessment of patients with ED or, in patients presenting with $\mathrm{ED}$, may induce investigation of any underlying potential comorbidities.

\section{REFERENCES}

1. National Institutes of Health Consensus Development Panel on Impotence: Impotence. JAMA 270: 83-90, 1993.

2. Melman A, and Gingell JC: The epidemiology and pathophysiology of erectile dysfunction. J Urol 161: 5-11, 1999.

3. Moreira ED Jr, Lôbo CFL, and Glasser D: A populationbased survey to determine the prevalence of erectile dysfunction and its correlates in the State of Bahia, Northeastern Brazil. J Urol 163(suppl): 15, 2000.

4. Krane RJ, Goldstein I, and Saenz de Tejada I: Impotence. N Engl J Med 321: 1648-1659, 1989.

5. Boolell M, Gepi-Attee S, Gingell JC, et al: Sildenafil, a novel effective oral therapy for male erectile dysfunction. Br J Urol 78: 257-261, 1996.

6. Morales A, Heaton JP, Johnston B, et al: Oral and topical treatment of erectile dysfunction: present and future. Urol Clin North Am 22: 879-886, 1995.

7. Abdo CHN, Moreira ED Jr, and Fittipaldi JAS: Estudo do comportamento sexual no Brasil - ECOS. Rev Bras Med 57: 1329-1335, 2000.

8. Feldman HA, Goldstein I, Hatzichristou DG, et al: Construction of a surrogate variable for impotence in the Massachusetts Male Aging Study. J Clin Epidemiol 47: 457-467, 1994.

9. Derby CA, Araujo AB, Johannes CB, et al: Measurement of erectile dysfunction in population-based studies: the use of a single question self-assessment in the Massachusetts Male Aging Study. Int J Impot Res 12: 197-204, 2000.

10. Rosen RC, Riley A, Wagner G, et al: The international index of erectile function (IIEF): a multidimensional scale for assessment of erectile dysfunction. Urology 49: 822-830, 1997.

11. O'Leary MP, Fowler FJ, Lenderking WR, et al: A brief male sexual function inventory for urology. Urology 46: 697706, 1995.

12. Instituto Brasileiro de Geografia e Estatística: Anuário Estatístico do Brasil-1996. Rio de Janeiro, Ministério Brasileiro do Planejamento e Orçamento, 1997.

13. Feldman HA, Goldstein I, Hatzichristou DG, et al: Impotence and its medical and psychosocial correlates: results of the Massachusetts Male Aging Study. J Urol 151: 54-61, 1994.

14. Ansong KS, Lewis C, Jenkins P, et al: Epidemiology of erectile dysfunction: a community-based study in rural New York State. Ann Epidemiol 10: 293-296, 2000.

15. Virag R, and Beck-Ardilly L: Nosology, epidemiology, clinical quantification of erectile dysfunctions. Rev Med Interne 18(suppl 1): 10S-13S, 1997.

16. Thai Erectile Dysfunction Epidemiologic Study Group (TEDES): An epidemiological study of erectile dysfunction in Thailand. Part 1: prevalence. J Med Assoc Thai 83: 872-879, 2000.

17. Laumann EO, Paik A, and Rosen RC: The epidemiology of erectile dysfunction: results from the National Health and Social Life Survey. Int J Impot Res 11(suppl 1): S60-S64, 1999.

18. Johannes CB, Araujo AB, Feldman HA, et al: Incidence of erectile dysfunction in men 40 to 69 years old: longitudinal results from the Massachusetts Male Aging Study. J Urol 163: 460-463, 2000.

19. Aytaç IA, Araujo AB, Johannes CB, et al: Socioeconomic factors and incidence of erectile dysfunction: findings of the longitudinal Massachusetts Male Aging Study. Soc Sci Med 51: 771-778, 2000.

20. Jonler M, Moon T, Brannan W, et al: The effect of age, ethnicity and geographical location on impotence and quality of life. Br J Urol 75: 651-655, 1995.

21. Fedele D, Bortolotti A, Coscelli C, et al, on behalf of the Gruppo Italiano Studio Deficit Erettile nei Diabetici: Erectile dysfunction in type 1 and type 2 diabetics in Italy. Int J Epidemiol 29: 524-531, 2000.

22. Kayigil O, Atahan O, and Metin A: Multifactorial evaluation of diabetic erectile dysfunction. Int Urol Nephrol 28: 717-721, 1996.

23. Cummings $\mathrm{MH}$, and Alexander WD: Erectile dysfunction in patients with diabetes. Hosp Med 60: 638-644, 1999.

24. Jevtich MJ, Edson M, Jarman WD, et al: Vascular factor in erectile failure among diabetics. Urology 19: 163-168, 1982.

25. Saenz de Tejada I, Goldstein I, Azadzoi K, et al: Impaired neurogenic and endothelium-mediated relaxation of penile smooth muscle from diabetic men with impotence. N Engl J Med 320: 1025-1030, 1989.

26. Andersson $\mathrm{K}$, and Stief $\mathrm{C}$ : Penile erection and cardiac risk: pathophysiologic and pharmacologic mechanisms. Am J Cardiol 86: 23F-26F, 2000.

27. Feldman HA, Johannes CB, Derby CA, et al: Erectile dysfunction and coronary risk factors: prospective results from the Massachusetts Male Aging Study. Prev Med 30: $328-$ 338, 2000.

28. Araujo AB, Johannes CB, Feldman HA, et al: Relation between psychosocial risk factors and incident erectile dysfunction: prospective results from the Massachusetts Male Aging Study. Am J Epidemiol 152: 533-541, 2000.

29. Seidman SN, and Roose SP: The relationship between depression and erectile dysfunction. Curr Psychiatry Rep 2: 201-205, 2000.

30. Shabsigh R, Klein LT, Seidman S, et al: Increased incidence of depressive symptoms in men with erectile dysfunction. Urology 52: 848-852, 1998. 